\title{
Non-invasive pneumococcal pneumonia due to vaccine serotypes: A systematic review and meta-analysis
}

\author{
Louise Lansbury, ${ }^{a, b *}$ Benjamin Lim, ${ }^{c}$ Tricia M McKeever, ${ }^{a, b}$ Hannah Lawrence, ${ }^{a, b, d}$ and Wei Shen Lim ${ }^{b, d}$ \\ ${ }^{\mathrm{a}}$ Division of Epidemiology and Public Health, University of Nottingham, Nottingham, UK \\ ${ }^{\mathrm{b}}$ National Institute for Health Research (NIHR) Nottingham Biomedical Research Centre, UK \\ 'Faculty of Biology (School of Medicine), University of Cambridge, Cambridge, UK \\ ${ }^{\mathrm{d} D e p a r t m e n t}$ of Respiratory Medicine, Nottingham University Hospitals NHS Trust, Nottingham, UK
}

\begin{abstract}
Summary
Background Non-invasive pneumococcal pneumonia causes significant morbidity and mortality in older adults. Understanding pneumococcal sero-epidemiology in adults $\geq 50$ years is necessary to inform vaccination policies and the updating of pneumococcal vaccines.
\end{abstract}

Methods We conducted a systematic review and random-effects meta-analysis to determine the proportion of community-acquired pneumonia (CAP) in people $\geq 50$ years due to pneumococcus and the proportion caused by pneumococcal vaccine serotypes. We searched MEDLINE, EMBASE and PubMed from I January 1990 to 30 March 202I. Heterogeneity was explored by subgroup analysis according to a) patient group (stratified versus age) and depth of testing, b) detection/serotyping method, and c) continent. The protocol is registered with PROSPERO (CRD42020192002).

Findings Twenty-eight studies were included $(34,216$ patients). In the period $\mathrm{I}-5$ years after introduction of childhood PCVIo/13 immunisation, I8\% of CAP cases (95\% CI 13-24\%) were attributable to pneumococcus, with $49 \%$ (43-54\%) of pneumococcal CAP due to PCVI3 serotypes. The estimated proportion of pneumococcal CAP was highest in one study that used 24-valent serotype-specific urinary-antigen detection (ss-UAD)(30\% [28-31\%]), followed by studies based on diagnostic serology (28\% [24-33\%]), PCR (26\% [15-37\%]), ss-UADI4 (I7\% [13-22\%]), and culture alone (I4\% [10-19\%]). A higher estimate was observed in Europe (26\% [2I-30\%] than North America (II\% [9 $-\mathrm{I} 2 \%](p<0 \cdot 00 \mathrm{I})$. PCVI3-serotype estimates were also influenced by serotyping methods.

Interpretation Non-invasive pneumococcal CAP and vaccine-type pneumococcal CAP remains a burden in older adults despite widespread introduction of pneumococcal infant immunisation. Studies heavily reliant on ss-UADs restricted to vaccine-type serotypes may overestimate the proportion of potentially vaccine-preventable pneumococcal pneumonia. Sero-epidemiological data from low-income countries are lacking.

Copyright $\odot 2022$ The Authors. Published by Elsevier Ltd. This is an open access article under the CC BY license (http://creativecommons.org/licenses/by/4.0/)

Keywords: Pneumonia; Streptococcus pneumoniae; Pneumococcal vaccines; Serotype; Older adults

\section{Introduction}

Community-acquired pneumonia (CAP) is a significant cause of morbidity and mortality worldwide., ${ }^{\mathrm{I}, 2}$ Streptococcus pneumoniae (pneumococcus) is the most commonly implicated bacterial pathogen, ${ }^{3-7}$ and the spectrum of pneumococcal disease ranges from asymptomatic nasopharyngeal carriage through to localised infections and invasive pneumococcal disease (IPD),

*Corresponding author at: Division of Epidemiology and Public Health, University of Nottingham, Nottingham, NG5 IPB, United Kingdom.

E-mail address: Louise.Lansbury@nottingham.ac.uk (L. Lansbury). although non-invasive pneumococcal pneumonia is the most common manifestation. ${ }^{8}$ The Global Burden of Diseases Study estimated that in 2016 pneumococcal lower respiratory infections caused around $\mathrm{I} \cdot 2$ million deaths worldwide and I97 million episodes. 9 The burden of pneumococcal disease follows a U-shaped curve, with greatest incidence and mortality in young children under 5 years and older adults aged 65 and above., ${ }^{2,9, \text { IO }}$

With roo documented pneumococcal serotypes, which vary in their disease severity, invasiveness and antimicrobial susceptibility, pneumococcal disease is at least partially vaccine-preventable. Many countries around the world have established infant immunisation programmes against pneumococcal disease, most using
eClinicalMedicine 2022;44: 101271 Published online $x x x$ https://doi.org/10.1016/j. eclinm.2022.101271 


\section{Research in context}

Evidence before this study

We searched Medline, Embase and PubMed from 1 January 1990 to 30 March 2021, with no restriction by language, for studies evaluating the proportion of noninvasive pneumococcal pneumonia in adults aged 50 years and above caused by serotypes included in pneumococcal vaccines across the world. Observational studies have differed widely in the reported contribution of vaccine-type serotypes to non-invasive disease (from $25 \%$ to $80 \%$ ), likely reflecting the use of different diagnostic and serotyping techniques, regional epidemiology and the impacts of national pneumococcal vaccination programmes. Our search did not reveal any previous systematic reviews that have assessed the impact of these factors on estimates of pneumococcal pneumonia and vaccine-preventable disease in older adults globally.

\section{Added value of this study}

This systematic review and meta-analysis, conducted at the request of the WHO Pneumococcal SAGE Working Group, is the first to focus on the impact of pneumococcal serotypes on non-invasive pneumococcal CAP in adults aged 50 years and above. We included 28 eligible studies (34,216 patients) from different parts of the world and have shown that pneumococcal serotypes included in current pneumococcal vaccines still cause a persistent burden of potentially vaccine preventable non-invasive CAP in older people despite the widespread introduction of infant immunisation with pneumococcal conjugate vaccines. Furthermore, we highlight the effect of pneumococcal diagnostic/serotyping method and geographical location on the estimates of pneumococcal and vaccinetype CAP, and identify an important evidence-gap through the absence of data from low-middle income countries (LMICS) where the burden from pneumonia remains very high.

\section{Implications of all the available evidence}

Strategies to further reduce the substantial proportion of vaccine-preventable non-invasive CAP in older people, despite infant pneumococcal immunisation programmes, warrant consideration. Studies from LMICs are required to guide global pneumococcal vaccination policies as there are currently no serotype specific data for non-invasive disease from these countries. Future studies should be supported by the development of improved serotype-specific diagnostic methods which detect a wide range of serotypes not restricted to those in existing vaccines so that changes in non-vaccine serotypes can be detected, and to reduce potentially biased estimates of vaccine-preventable disease.

either a I3-valent or Io-valent pneumococcal conjugate vaccine (PCV). Introduction of childhood PCV immunisation has been associated with a reduction of overall and serotype-specific IPD in young children. Furthermore, infant PCV immunisation reduces nasopharyngeal carriage in those who are vaccinated thus preventing onward transmission to unvaccinated children and adults, and has resulted in reductions in both IPD and pneumococcal pneumonia across all ages. ${ }^{\text {II-IS }}$ Some higher-income countries offer PPV23 and/or PCVI3 vaccination to high-risk adults, including those over 65 years, although uptake varies between countries and is poor in many countries in which the vaccine is available. ${ }^{\mathrm{I}, \mathrm{I7}}$

Most data on the epidemiology of vaccine-serotype pneumococcal disease is derived from invasive isolates, although fewer than Io\% of pneumococcal pneumonia cases are invasive. To inform effective global pneumococcal vaccination strategies it is important to understand the true burden of non-invasive pneumonia and the impact of current vaccination programmes on the sero-epidemiology of the disease in older people. The primary objective of this systematic review and meta-analysis was to summarise the evidence on the proportion of non-invasive pneumococcal CAP due to $S$. pneumoniae serotypes covered by the PCV and PPV23 vaccines in people who are 50 years or older, and the secondary objective to evaluate the proportion of non-invasive pneumococcal CAP due to S. pneumoniae. This systematic review and meta-analysis was conducted at the request of the WHO Pneumococcal SAGE Working Group and initial results were presented to the Working Group in August 2020.

\section{Methods}

We conducted this systematic review and meta-analysis in accordance with the Preferred Reporting Items for Systematic Reviews and Meta-Analyses (PRISMA) reporting guidelines. ${ }^{\mathrm{I} 8}$ The study protocol was registered with the National Institute for Health Research international prospective register of systematic reviews (PROSPERO) (CRD42020192002). ${ }^{\text {I9 }}$

\section{Search strategy}

We searched MEDLINE, EMBASE and PubMed from I January I990 up to 30 March 202I, using search terms relating to community-acquired pneumonia, Streptococcus pneumoniae, and pneumococcal serotypes. (See Supplementary Material I for example of the EMBASE search strategy). We also manually searched the reference lists of included articles for relevant studies. No language restrictions were imposed.

\section{Study selection}

We included cohort studies, surveillance studies and registry studies reporting data on non-invasive pneumococcal pneumonia caused by serotypes included in the study country's national pneumococcal immunisation 
schedule. Studies were eligible if they had separate pneumococcal data for adults aged 50 years or above, either stratified according to age group or in which the overall mean or median age of the entire cohort was $\geq 50$ years, with a diagnosis of pneumonia acquired in the community. We excluded experimental studies, case-control studies, editorials, reviews and meta-analyses, studies with insufficient data on the pneumococcal serotypes causing non-invasive pneumonia in people aged 50 years and older, and studies which only included patients with invasive pneumococcal disease. One author (LL) screened the titles using pre-specified inclusion and exclusion criteria. Abstract and full text screening was independently performed by two authors (LL and HL/BL/TM) with disagreements resolved by consensus.

\section{Data extraction and analysis}

Two reviewers (LL and HL/BL/TM) independently extracted data from individual studies using a predefined piloted template. We collected data on study methodology, location and setting, study population, national pneumococcal immunisation schedule including type and date of introduction, the incidence and proportion of CAP patients with pneumonia due to $S$. pneumoniae and the proportion of those due to vaccine serotypes, and the methods used to diagnose pneumococcal pneumonia and to identify pneumococcal serotypes. We assessed the risk of bias in the study group selection and outcome domains using a modification of the Newcastle-Ottawa Scale. ${ }^{20}$ The comparability domain was not considered relevant due to the design of the included studies.

\section{Outcome measures}

Outcome measures were the proportion of CAP caused by $S$. pneumoniae in people aged 50 years and over, and the proportion of pneumococcal pneumonia in patients aged 50 and over in whom a vaccine type (VT) pneumococcus was identified as the causative pathogen. The serotypes covered by each of the currently licensed pneumococcal vaccines are listed in supplement 2 .

\section{Data synthesis}

We estimated the pooled proportion using the metaprop command in Stata and a random effects model. ${ }^{2 \mathrm{I}}$ Variances were stabilised using the Freeman-Tukey double arcsine transformation which normalises the outcomes before pooling so that studies with proportions close to ०\% or 100\% were approximately estimated. For a study $i$, in which ri denotes the number of observations with a certain characteristic and $\mathrm{ni}$ is the total number of observations, this is defined as: $\sin ^{-1} \sqrt{\frac{r i}{n i+\mathrm{I}}}+\sin ^{-\mathrm{I}} \sqrt{\frac{r i+\mathrm{I}}{n i+\mathrm{I}}}$

The asymptotic variance of the transformed variable is defined as:

$\frac{\mathrm{I}}{n i+0.5}$

The DerSimonian Laird method was used to compute pooled estimates based on the transformed values and their variances.

We assessed heterogeneity using the $\mathrm{I}^{2}$ statistic.

We estimated the proportion of a) patients aged 50 and above with CAP caused by pneumococcus; b) patients aged 50 and above with pneumococcal pneumonia caused by a serotype covered by PCVI3 and PPV23. Analyses were stratified by: patient group (entire cohort aged $\geq 50$ years or median/mean $\geq 50$ years) and completeness of testing (with optimal testing defined as simultaneous testing by culture, BinaxNOW (non-specific pneumococcal antigen test) and serotype-specific urinary antigen detection (ss-UAD)/serotype specific serology); by serotype detection method (UAD24, UADI4, serology, PCR, respiratory culture only); and by continent (Asia, Europe and North America). Data were analysed for the periods pre- and post-introduction of childhood PCVıо/13 immunisation programmes, with data for the post-PCV Io/I3 period being included if collected at least one year after national introduction of PCVIo/I3.

All analyses were conducted in Stata $16 \cdot 0$ software (StataCorp. 20I9. Stata Statistical Software: Release I6. College Station, TX:StatCorp LLC.).

\section{Ethics statement}

Ethical approval for this systematic review and metaanalysis is not applicable since the data utilised were collected from previously published research in the literature. All the included studies in this review had received ethical approval prior to data collection.

\section{Role of the funding source}

The funders had no role in the study design, data collection, data analysis, data interpretation, or in the writing of the manuscript.

\section{Results}

After screening 347I papers, 28 studies were eligible for inclusion (Figure I) I $^{15,22-48}$ and included data on 34,2I6 patients from i9 countries across Asia, Europe and North America (supplementary Table I). All studies were from high income countries. The most common reasons for exclusion of studies were wrong age group and inadequacy of serotype data. 

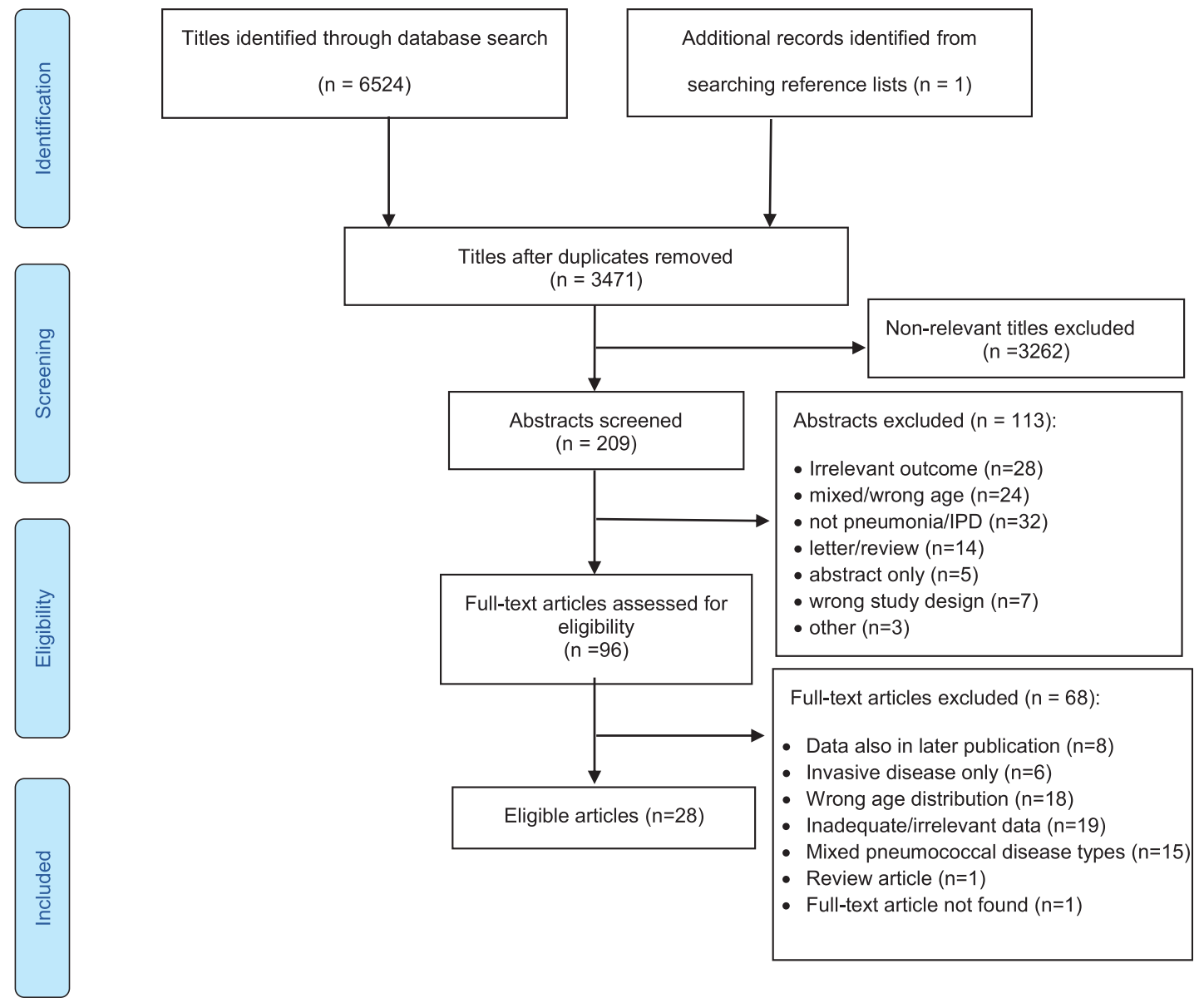

Figure 1. PRISMA flow diagram for study selection.

In the modified risk of bias assessment, 8 of the 28 (28.6\%) studies were judged to have some degree of selection bias as included patients may have not been truly representative of patients with CAP (Supplementary Table 2).

\section{Proportion of CAP due to Streptococcus pneumoniae}

Prior to introduction of childhood PCVIO/I3 immunisation, the pooled estimated proportion of CAP which was due to pneumococcus in people aged 50 years and above was $22 \% \quad(95 \%$ CI I5-29\%, 6 studies, $\left.\mathrm{I}^{2}=97 \cdot \mathrm{I} \%\right),{ }^{\mathrm{I}, 25,27,42,44,46}$ ranging from $\mathrm{I} 2 \%$ to $38 \%$. (Supplementary Figure I) Eleven studies included data from at least one year after the introduction of PCVIO/I3, with a pooled proportion of $\mathrm{I} 8 \%\left(95 \% \mathrm{CI} \mathrm{I}_{3}-24 \%, \mathrm{I}^{2}=\right.$ $98 \cdot 9 \%$ ), ranging from $9 \%$ to $32 \% .^{15,22,24,25,27,30,31,33,37,39,41}$ The estimated proportion of CAP due to pneumococcus was influenced by the testing method, with stratification according to pneumococcal detection method showing significant subgroup heterogeneity $(p<0.00 \mathrm{I})$. The highest estimated proportion of CAP due to pneumococcus was seen with ss-UAD24 (30\% [95\% CI 28-31\%], I study), followed by serology (28\% [95\% CI 24-33\%], 2 datasets), PCR (26\% [95\% CI I5-37\%], 2 studies), ssUADi4 (I7\% [95\% CI I3-22\%, 9 datasets), and culture alone (I4\% [95\% CI I0-I9\%], 3 datasets). (Figure 2)

Significant heterogeneity was noted between studies stratified by continent $(p<0.00 \mathrm{I})$ (Figure 3$)$. In the post PCVIO/I3 period, the summary estimate for the proportion of CAP due to pneumococcus from six studies in Europe was $26 \%(95 \%$ CI $2 \mathrm{I}-30 \%$, $\left.\mathrm{I}^{2}=92 \%\right),{ }^{\mathrm{I}, 24,25,30,33,4 \mathrm{I}}$ whereas from four North American studies it was II\% (95\% CI 9-I2\%, $\left.\mathrm{I}^{2}=87 \cdot 2 \%\right) .^{22,3 \mathrm{I}, 37,39}$ Similarly, one study from Korea also reported a proportion of $\mathrm{II} \%$ (95\% CI 9- $13 \%$ ), although this was based on serotyped isolates from bacterial culture rather than Ss-UAD testing so may be an underestimate of the true proportion. ${ }^{27}$

No significant subgroup differences were observed when studies were grouped by definition of age groups (defined strata versus mean/median age) $(p=0.64)$, nor by depth of testing (optimal versus sub-optimal) $(p=0 \cdot 7 \mathrm{I})$ (Supplementary Figures 2 and 3$)$. 


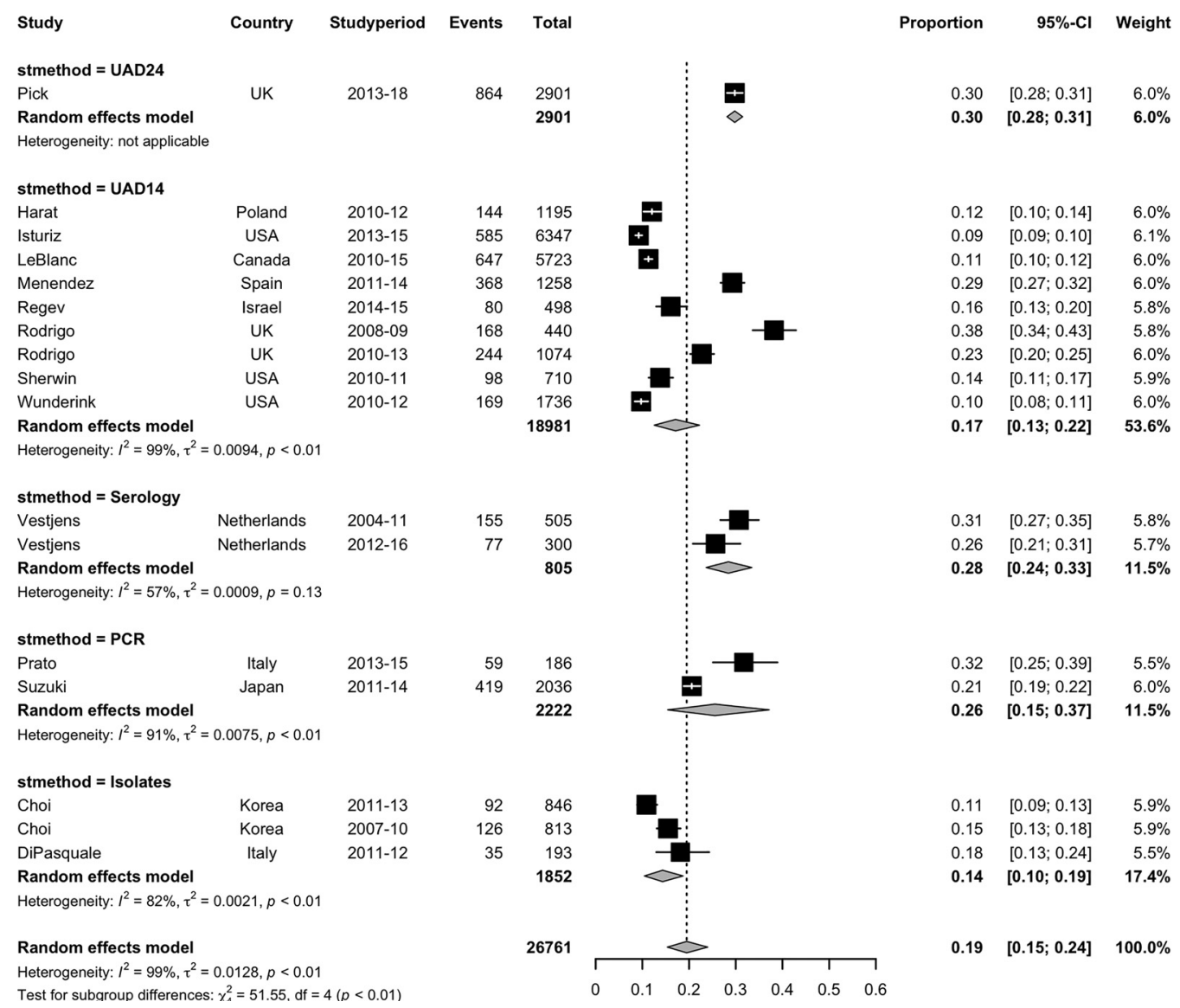

Figure 2. Forest plot of the pooled estimated proportion of CAP due to Streptococcus pneumoniae, stratified by the method of pneumococcal serotyping employed by included studies.

Key: UAD24: 24-valent serotype-specific urinary antigen detection,

UAD14: 14-valent serotype-specific urinary antigen detection,

PCR: polymerase chain reaction (S. pneumoniae isolated by PCR with sequential multiplex PCR using 29 serotype specific primer pairs).

Sensitivity analysis excluding 1 study (di Pasquale) considered to be at risk of some selection bias:

UAD24: 30\% (28-31),

UAD14: $17 \%(13-22)$,

Serology: $28 \%(24-33)$,

PCR: $26 \%(15-37)$

Isolates: $13 \%(11-15)$,

Overall $\mathrm{I}^{2}=98.75 \%$.

\section{Proportion of pneumococcal CAP due to PCV13 serotypes}

The overall pooled proportion of pneumococcal CAP which was due to $\mathrm{PCV}$ i3 serotypes in the $\mathrm{I}-5$ years post PCVIo/I3 period was $49 \%$ (95\% CI $43-54 \%$, I5 studies, I9 datasets, $I^{2}=92 \cdot 7 \%$ )(Supplementary Figure 4 ). For studies in which pneumococcal testing was optimal and which stratified by age, the pooled proportion of pneumococcal CAP due to PCVi3 serotypes was similar to the overall estimate, $51 \%(95 \%$ CI $43-59 \%$, 7 studies, $\left.\mathrm{I}^{2}=92 \cdot 7 \%\right)^{\mathrm{I} 5,22,30,3 \mathrm{~T}, 37-39,4 \mathrm{I}}$ The pooled proportion of all CAP due to PCVi3 serotypes from these same studies was $8 \%\left(95 \%\right.$ CI $\left.6-\mathrm{II} \%, \mathrm{I}^{2}=97 \cdot \mathrm{I} \%\right)$.
Again, the estimates were influenced by the method of pneumococcal serotype detection (Figure 4). The highest estimated proportion of pneumococcal CAP due to PCVI3 serotypes was observed in one study in which sequential-multiplex PCR was used for serotyping using 29 serotype-specific primer pairs $(66 \%, 95 \%$ CI $53-78 \%$ ). ${ }^{33}$ The estimated pooled proportion of pneumococcal CAP due to PCVI3 serotypes from studies employing a I4-valent ss-UAD was $56 \%(95 \%$ CI 49 $-63 \%, 8$ studies, $\mathrm{I}^{2}=90 \cdot 2 \%$ ), $15,22,24,30,3 \mathrm{~T}, 37-39$ and $40 \%$ $\left(95 \% \mathrm{CI} 34-46 \%, \mathrm{I}^{2}=80 \cdot 4 \%\right)$ from six studies in which serotyping was performed on isolates only. ${ }^{26-29,35,43}$ In the one study which utilised a 24 -valent ss-UAD, the 


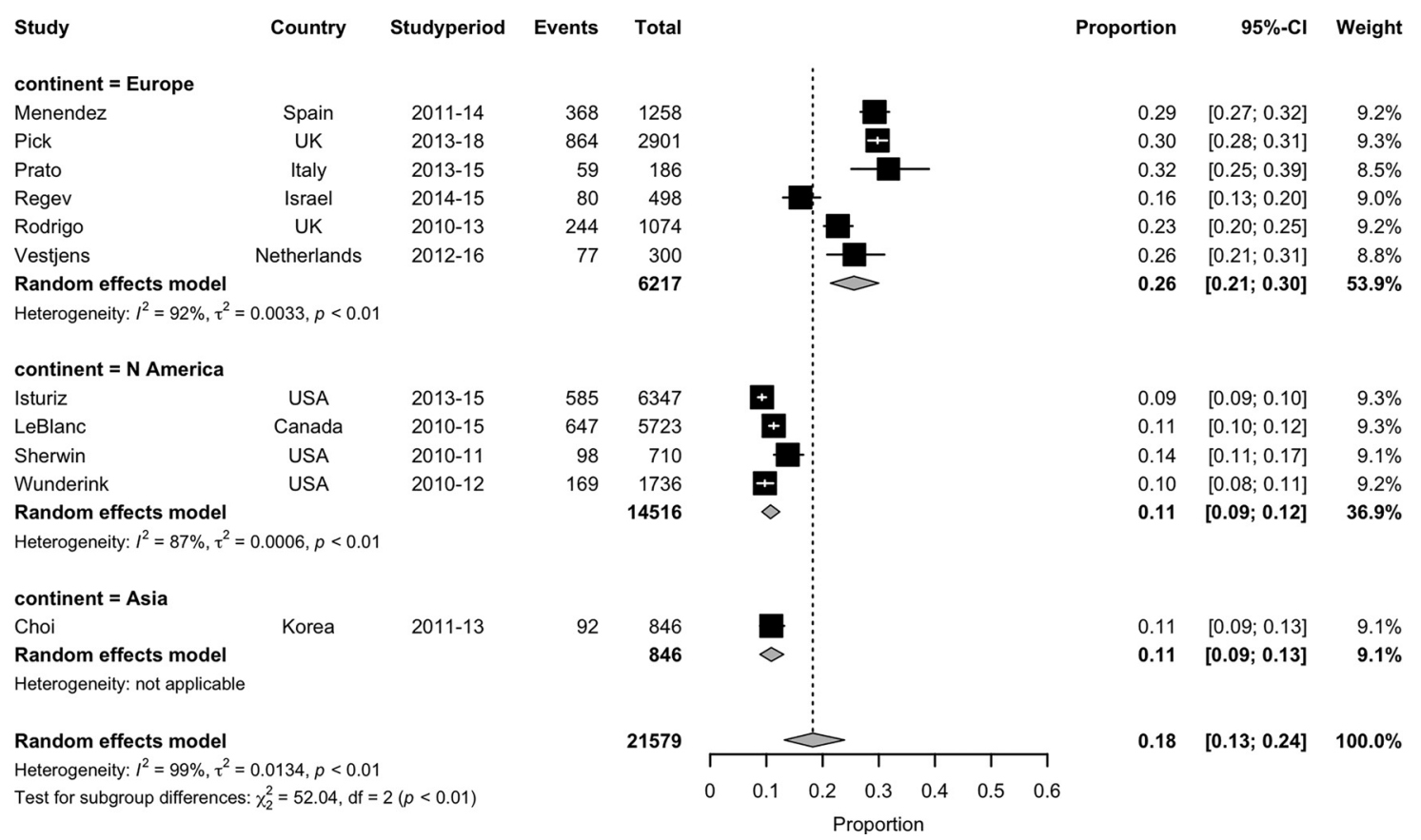

Figure 3. Estimated proportion CAP due to S. pneumoniae stratified by continent.

proportion of pneumococcal CAP due to PCV-I3 serotypes was $37 \%$ (95\% CI $33-40 \%) .^{4^{\mathrm{I}}}$

By continent, the highest proportion of pneumococcal CAP caused by PCVI3 serotypes was noted when studies from North America were pooled, all of which employed ss-UADi4 (59\%, 95\% CI 47-71\%, 4 studies, $\left.\mathrm{I}^{2}=95 \%\right),{ }^{22,3 \mathrm{I}, 37,39}$ followed by Europe $(48 \%, 95 \%$ CI 40 $-56 \%, 8$ studies, $\left.\mathrm{I}^{2}=94.3 \%\right)$ for which serotyping methods varied between the included studies. . $^{154,28,30,33,38,4 \mathrm{I}, 43}$ The pooled estimate was lowest in studies from Asia, all of which were based on serotyping of pneumococcal isolates (4I\%, 95\% CI 34 $-49 \%, 4$ studies, $I^{2}=70 \cdot 1 \%$ ). ${ }^{26,27,29,35}$ (Supplementary Figure 5)

\section{Proportion of pneumococcal CAP due to PPV23 serotypes}

The overall pooled estimate of the proportion of pneumococcal CAP due to PPV23 serotypes, including those in PCVI3, was $67 \%$ (95\% CI 62-72\%, I2 studies, $\left.\mathrm{I}^{2}=90.3 \%\right)$. Two studies which used PCR for serotyping had a pooled estimated proportion of $80 \%$ (95\% CI 75 $-83 \%)$. One of these studies examined for 50 pneumococcal serotypes by nanofluidic real-time PCR and the second employed 29 primer pairs to serotype pneumococcus PCR-positive samples. ${ }^{33,46}$ The proportion of CAP due to PPV23 serotypes in the one study which used SS-UAD24 to detect pneumococci was 70\% (95\% CI $66-73 \%) \cdot{ }^{4 I}$ Pooling data from the nine studies which serotyped using the Quellung method on pneumococcal isolates only gave the lowest estimated proportion of CAP due to PPV23 serotypes at 65\% (95\% CI $\left.58-7 \mathrm{I} \%, \mathrm{I}^{2}=88 \cdot 2 \%\right) .{ }^{26-29,32,35,40,43,45}$ (Supplementary Figure 6)

\section{Prevalent pneumococcal serotypes in CAP}

The most prevalent pneumococcal serotypes for each study are presented in Table I. Overall serotype 3 ranked as one of the top three most prevalent serotypes in 25 of $30(83.3 \%)$ datasets for non-bacteraemic CAP, followed by I9A $(53.3 \%$ of datasets), and IIA/E and I9F (both $30 \%$ of datasets).

\section{Trends in vaccine-type CAP post PCV10/13 infant immunisation}

Overall trends in vaccine serotype and non-vaccine serotype pneumococcal pneumonia are described in Table 2.

\section{Discussion}

Our systematic review and meta-analysis indicates that in people $\geq 5$ o years, the proportion of CAP due to pneumococcus has remained substantial even after the introduction of infant immunisation programmes using PCV vaccines, ranging from $9 \%$ up to $30 \%$ in the included studies. Overall, almost $50 \%$ of serotypes causing pneumococcal CAP were covered by the PCVI3, ranging from $25 \%$ to $80 \%$, and $67 \%$ by $\mathrm{PPV} 23$, ranging from $50 \%$ to $82 \%$ in individual studies. 


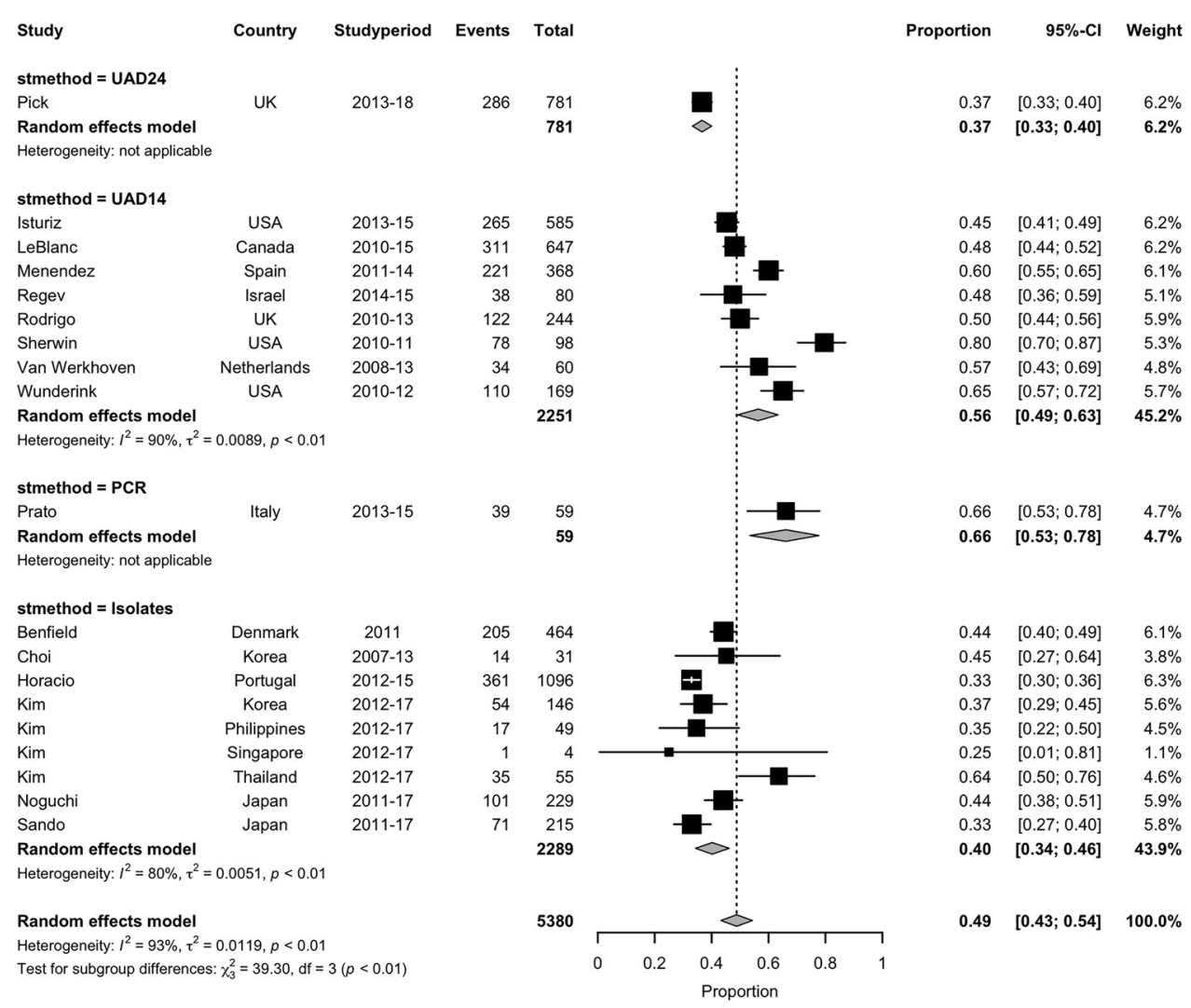

Figure 4. Estimated proportion of pneumococcal CAP due to PCV13 vaccine serotypes in the period after introduction of PCV10/13 immunisation programmes, stratified by the method of pneumococcal serotyping employed by included studies. Legend: Sensitivity analysis excluding 4 studies (Benfield, Horacio, Kim, Sando) considered to be at risk of some selection bias:

UAD24: $37 \%(33-40)$,

UAD14: $56 \%(49-63)$,

PCR: $66 \%(53-77)$,

Isolates: $54 \%(47-60)$,

Overall $\mathrm{I}^{2}=92.14 \%$.

Of the factors influencing the results, the type of testing employed for pneumococcal detection and serotyping had a significant impact on the estimated proportions with lower estimates from those studies in which conventional techniques only were employed compared to newer methods such as Ss-UAD and PCR. Serotype-specific multiplex urinary immunoassays have been developed which detect specific pneumococcal serotypes covered by PCVI3 and/or PPV23.49-5I These ss-UADs detect additional pneumococcal cases of CAP that would otherwise be missed by traditional culture or BinaxNOW alone. ${ }^{37,39}$ These non-cultural tests (ss-UAD or PCR) have a higher sensitivity for the detection of pneumococcal infection compared to conventional culture with serotyping of isolates using the Quellung reaction. Consequently, studies that rely heavily on ss-UADs for the detection of pneumococcal cases will over-estimate the proportion of pneumococcal CAP due to the serotypes detected by the ss-UADs used; for ss-UADi4 and Ss-UAD24 these correspond largely to the VTs in
PCVI3 and PPV23 respectively. It should also be considered that the higher sensitivity of ss-UADs and PCR tests may be detecting pneumococcal carriage and not true lower respiratory tract infection. Conversely, studies using traditional detection methods such as blood and/or sputum culture alone are likely to underestimate the true burden of pneumococcus. The diagnostic sensitivity of sputum culture is highly variable and will depend upon the quality of the sample, processing delays and prior antimicrobial therapy, and false positives from upper respiratory tract carriage may occur. ${ }^{52}$

Detection of pneumococcal C-polysaccharide antigen by the BinaxNOW urinary antigen test has been estimated to have increased diagnosis of pneumococcal CAP by II $-23 \%$ beyond conventional culture ${ }^{53,54}$ It has an estimated sensitivity and specificity of $75 \%$ and $95 \%$ respectively, ${ }^{53-56}$ although several studies found that sensitivity is higher for bacteraemic than non-bacteraemic pneumonia $(77-92 \%$ and $52-78 \%$ respectively). $57-60$ 


\begin{tabular}{|c|c|c|c|c|c|}
\hline Study & Country & Year & $\begin{array}{l}\text { Pre } \mathrm{PCV}^{\mathrm{a}} / \text { Years } \\
\text { post } \mathrm{PCV} \text { infant } \\
\text { immunisation }\end{array}$ & $\begin{array}{l}\text { Number of } \\
\text { people } \\
\text { included }\end{array}$ & Most prevalent serotypes \\
\hline \multicolumn{6}{|l|}{ Europe } \\
\hline \multirow{2}{*}{ Domenech $^{45}$} & Spain & $2001-8$ & Pre & 255 & 3, 1,5 (bacteraemic) \\
\hline & & & & & 3, 19F, $23 \mathrm{~F}$ (non-bacteraemic) \\
\hline Harat $^{42}$ & Poland & 2010-12 & Pre & 1195 & $3,23 \mathrm{~F}, 18 \mathrm{C}$ \\
\hline Pletz $^{34}$ & Germany & $2002-11$ & Pre & 391 & $7 F, 3,1$ \\
\hline Vila Corcoles ${ }^{40}$ & Spain & $2008-11$ & Pre & 125 & $3,19 \mathrm{~A}, 22 \mathrm{~F}$ \\
\hline Horacio $^{36}$ & Portugal & 1999-2011 & Pre to 1 & 225 & $3,11 \mathrm{~A}, 19 \mathrm{~F}$ \\
\hline \multirow[t]{2}{*}{ Benfield ${ }^{43}$} & Denmark & 2011 & 1 & 464 & 3, 11A,19A (non-bacteraemic) \\
\hline & & & & & 1, $7 F, 3$ (bacteraemic) \\
\hline Van Werkhoven ${ }^{38}$ & Netherlands & 2011-13 & Up to 2 & 288 & $3,7 F, 19 \mathrm{~A}$ \\
\hline Rodrigo $^{15}$ & UK & $2008-13$ & Up to 3 & 1887 & $1,7 \mathrm{~F} / \mathrm{A}, 19 \mathrm{~A}$ \\
\hline Menende $z^{24}$ & Spain & $2011-14$ & $1-3$ & 1258 & $3,7 \mathrm{~F}, 19 \mathrm{~A}$ \\
\hline Di Pasquale ${ }^{44}$ & Italy & $2011-12$ & $2-3$ & 193 & $35 F, 3,24$ \\
\hline $\operatorname{Regev}^{30}$ & Israel & $2014-15$ & 4 & 498 & $3,23 \mathrm{~F}, 19 \mathrm{~A}$ \\
\hline Vestjens $^{25}$ & Netherlands & $2012-16$ & $1-5$ & 805 & $3,8,19 \mathrm{~A}$ \\
\hline Horacio $^{28}$ & Portugal & $2012-15$ & $2-5$ & 1096 & $3,11 \mathrm{~A}, 19 \mathrm{~F}$ \\
\hline Prato $^{33}$ & Italy & $2013-15$ & $3-5$ & 186 & $23 \mathrm{~F}, 9 \mathrm{~V}, 19 \mathrm{~A}$ \\
\hline \multirow[t]{2}{*}{ Quirk ${ }^{48}$} & Iceland & $2009-17$ & Pre, up to 6 & 430 & $19 F, 6 B, 3$ \\
\hline & & & & & $19 \mathrm{~F}, 3,11 \mathrm{~A}$ \\
\hline Pick $^{41}$ & UK & $2013-18$ & $3-8$ & 2901 & $3,8,15 \mathrm{~A}$ \\
\hline \multicolumn{6}{|l|}{ North America } \\
\hline Sherwin ${ }^{31}$ & USA & 2010-11 & 1 & 710 & $19 \mathrm{~A}, 7 \mathrm{~F} / \mathrm{A}, 3$ and 5 \\
\hline Wunderink $^{37}$ & USA & $2010-12$ & Up to 2 & 2736 & $19 \mathrm{~A}, 3,7 \mathrm{~F}$ \\
\hline LeBlanc ${ }^{22,47}$ & Canada & $2011-15$ & $1-5$ & 5723 & $3,7 \mathrm{~F}, 19 \mathrm{~A}$ \\
\hline Isturiz ${ }^{39}$ & USA & $2013-16$ & $3-5$ & 6347 & $19 \mathrm{~A}, 3,5$ \\
\hline \multicolumn{6}{|l|}{ Asia } \\
\hline Oishi ${ }^{32}$ & Japan & 2001-03 & Pre & 114 & $19 \mathrm{~F}, 23 \mathrm{~F}, 6 \mathrm{~B}$ \\
\hline Morimoto $^{23}$ & Japan & 2011-13 & Pre & 1772 & $3,11 \mathrm{~A}, 19 \mathrm{~F}$ \\
\hline \multirow[t]{2}{*}{$\mathrm{Choi}^{27}$} & Korea & 2007-13 & Pre, up to 3 & 2221 & $3,19 \mathrm{~A}, 11 \mathrm{~A} / \mathrm{E}$ \\
\hline & & & & & $3,19 A, 6 C$ \\
\hline \multirow[t]{4}{*}{$\mathrm{Kim}^{26}$} & China & 2008-14 & Pre & 194 & $19 \mathrm{~F}, 19 \mathrm{~A}, 23 \mathrm{~F}$ \\
\hline & Korea & $2008-14$ & $2-5$ & 146 & $11 \mathrm{~A}, 19 \mathrm{~A}, 19 \mathrm{~F}$ \\
\hline & Philippines & $2008-14$ & $2-5$ & 49 & $3,11 \mathrm{~A}, 6 \mathrm{~B} / 19 \mathrm{~A}$ \\
\hline & Thailand & $2008-14$ & $1-4$ & 55 & $3,23 \mathrm{~F}, 6 \mathrm{~B}$ \\
\hline Suzuki ${ }^{46}$ & Japan & $2011-14$ & Up to 1 & 2036 & $3,10 \mathrm{~A}, 6 \mathrm{~A} / \mathrm{B}$ \\
\hline \multirow[t]{2}{*}{ Sando $^{35}$} & Japan & $2011-14,2016-17$ & Pre, 3 & 438 & $3,11 \mathrm{~A}, 19$ \\
\hline & & & & & $35 B, 3,6 C / 19 A$ \\
\hline Noguchi $^{29}$ & Japan & $2011-17$ & Up to 4 & 229 & $3,19 \mathrm{~F}, 11 \mathrm{~A} / \mathrm{E}$ \\
\hline
\end{tabular}

Sensitivity has also been shown to vary according to pneumococcal serotype and temporal changes in sensitivity have been associated with changes in the distribution of serotypes with time, sensitivity being highest for serotypes $9 \mathrm{~V}, \mathrm{I} 4, \mathrm{I} 8 \mathrm{C}$ and 20, and lowest for STs 8, 9 L/N, IIA, 23B and non-typeable serotypes. ${ }^{61}$

We observed that the proportion of CAP due to pneumococcus varied according to geographical region, with a pooled estimate of $26 \%$ from European studies compared to II\% in North America. This is in accordance with other studies which have found similar discrepancies between continents. ${ }^{62-64}$ This observation may represent a true difference in the proportion of CAP caused by pneumococcus and an increase in non-vaccine serotypes in both invasive and non-invasive pneumococcal disease in Europe which has not been seen in North 


\begin{tabular}{|c|c|c|}
\hline $\begin{array}{l}\text { Pneumococcal } \\
\text { Serotype }\end{array}$ & $\begin{array}{l}\text { Temporal trend in } \\
\text { serotypes causing } \\
\text { pneumococcal CAP }\end{array}$ & Studies reporting \\
\hline \multirow[t]{6}{*}{ PCV7 } & Overall decrease & $\begin{array}{l}\text { - Rodrigo }{ }^{15}: 88 \% \text { decrease pre to post } \mathrm{PCV}_{\mathrm{I} 3} \text { period (IRR/year } 0.84 \text { (95\% CI } 0.8-0.89 \text {, } \\
p<0.00 \mathrm{I}) \text { ) }\end{array}$ \\
\hline & & $\begin{array}{l}\text { - Sando }{ }^{35} \text { : Difference in hospitalised } \mathrm{PCV}_{7} \mathrm{ST} \text { pneumonia pre to } 3 \text { years post }=-\mathrm{II} \%(95 \% \mathrm{CI} \\
-\mathrm{I} 7 \cdot 7 \text { to }-4 \cdot 2, p=0.02)\end{array}$ \\
\hline & & $\begin{array}{l}\text { - Vestiens }{ }^{25} \text { : decrease between pre-PCVIo period up to } 2 \text { years post (OR 0.I9 (95\% CI 0.05 } \\
-0.76) \text { ) }\end{array}$ \\
\hline & & $\begin{array}{l}\text { Van Werkhoven }{ }^{38} \text { : decrease from } 28 \% \text { pre PCVIo to } 0.7 \% 2 \text { years post (p-value for trend } \\
0.048 \text { ) }\end{array}$ \\
\hline & & $\begin{array}{l}\text { - Noguchi } \mathrm{i}^{29} \text { : downward trend from } 46 \cdot 4 \% \text { in } 20 \text { II to } 4 \cdot 3 \% \text { in } 2014 \text { when PCVI3 licensed for } \\
\text { adults } \geq 65 \text { years }\end{array}$ \\
\hline & Persistence & $\begin{array}{l}\text { - Sherwin }{ }^{3 \mathrm{I}} \text { : persistence of } \mathrm{PCV}_{7} \text { STs I year after introduction of } \mathrm{PCV}_{13} \text { into paediatric } \\
\text { population }\end{array}$ \\
\hline \multirow[t]{4}{*}{ PCV13Non7 } & Overall decrease & $\begin{array}{l}\text { - Rodrigo }{ }^{\mathrm{I} 5}: 30 \% \text { decrease pre to post } \mathrm{PCV}_{\mathrm{I} 3} \text { period (IRR/year } 0.70(95 \% \mathrm{CI} 0.5 \mathrm{I}-0.96 \text {, } \\
p=0.024) \text {, but non-significant increase in STs } 6 \mathrm{~B} \text { and I9F in final year }\end{array}$ \\
\hline & & $\begin{array}{l}\text { - Sando } 35 \text { : Difference in hospitalised PCVIznon7 ST pneumonia pre to } 3 \text { years post }=-9 \% \\
(95 \% \text { CI }-17 \cdot 4 \text { to }-0.7, p=0.035)\end{array}$ \\
\hline & & $\begin{array}{l}\text { Wunderink }{ }^{37} \text { : non-significant decline up to } 2 \text { years post PCV introduction (adjusted OR } 0.65 \\
(95 \% \text { CI } \circ \cdot 4-\mathrm{I} \cdot 04)\end{array}$ \\
\hline & Persistence & $\begin{array}{l}\text { - Sherwin }{ }^{3 \mathrm{I}} \text { : persistence of } \mathrm{PCV}_{13} \mathrm{Non}_{7} \text { STs I year after introduction of } \mathrm{PCV}_{13} \text { into paediatric } \\
\text { population }\end{array}$ \\
\hline \multirow[t]{7}{*}{ PCV13 } & Overall decrease & $\begin{array}{l}\left.\text { - Horacio }{ }^{28} \text { : decrease from } 44 \% \text { in year of } \mathrm{PCV}_{13} \text { introduction to } 29 \cdot 7 \% \text { after } 5 \text { years } p<0 \cdot 00 \mathrm{I}\right) \\
\text { with decline in STs } 3 \text { and I9 }\end{array}$ \\
\hline & & $\begin{array}{l}\left.\text { - Sando } 0^{35} \text { : decrease in hospitalised PCVI3 ST pneumonia from } 53 \% \text { to } 33 \% \text { ( } p<0 \cdot 00 \mathrm{OI}\right) \text { pre to } \\
3 \text { years post PCV introduction }\end{array}$ \\
\hline & & - $\mathrm{Choi}^{27}$ : Non-significant trend towards decrease in first 2 years after introduction $(p=0.062)$ \\
\hline & & $\begin{array}{l}\text { Noguchi }{ }^{29} \text { : downward trend from } 7 \mathrm{I} \cdot 4 \% \text { in } 201 \mathrm{II} \text { to } 33 \cdot 3 \% \text { in } 2015 \text {, but no significant change } \\
\text { up to } 3 \text { years after PCVI3 licensed for adults } \geq 65 \text { years }\end{array}$ \\
\hline & & $\begin{array}{l}\text { - Isturiz } 39 \text { : Decline from } 5 \cdot 1 \% \text { to } 3 \cdot 4 \% \text { over } 3 \text { year study period up to } 5 \text { years after childhood } \\
\text { PCV and } 3 \text { years after ACIP recommendation of } \mathrm{PCV}_{13} \text { in adults } \geq 65 \text { years }(p=0 \cdot 0 \mathrm{OI}) \text {. Reduc- } \\
\text { tion in all PCVI3 STs except ST } 3\end{array}$ \\
\hline & & $\begin{array}{l}\text { - Menendez }{ }^{24} \text { : Non-significant decreasing trend from } 67 \cdot 4 \% \text { to } 52 \cdot \mathrm{I} \%(p=0.057) \text { from I to } \\
3 \text { years after infant PCVI3 introduction }\end{array}$ \\
\hline & & $\begin{array}{l}\text { LeBlan: } \mathrm{c}^{22} \text { Variable }- \text { highest incidence of } \mathrm{PCV}_{\mathrm{I} 3} \mathrm{STs} \text { in first } 3 \text { years after } \mathrm{PCV}_{\mathrm{I} 3} \text { introduc- } \\
\text { tion for infants, lowest in year } 4 \text { with significant decline in } 50-64 \text { year age group }(p=0.032] \text {. } \\
\text { Significant declines in } \mathrm{STs}_{7} \mathrm{~F} \text { in } \geq 65 \text { years and } \geq 50 \text { years during first } 3 \text { years }(p=0.048 \text { and } \\
\left.0.002 \text { respectively) and } \mathrm{ST}_{3} \text { in } \geq 65 \text { years } 9 \mathrm{p}=0.018\right) \text { although incidence of } \mathrm{ST}_{3} \text { increased } \\
\text { again } 4-5 \text { years after infant } \mathrm{PCV} \text { introduction in both in } \geq 65 \text { years and } \geq 50 \text { years }(p<0.00 \mathrm{I} \\
\text { and } p=0.00 \mathrm{I} \text { respectively). }\end{array}$ \\
\hline PCV10 & Overall decrease & $\begin{array}{l}\text { - Quirk }{ }^{48}: 403 \cdot 2 \text { to } 6 \mathrm{I} \cdot 7 / \mathrm{I} 00,000(p<0 \cdot 00 \mathrm{I}) \text { up to } 6 \text { years after introduction, significant } \\
\text { decline in STs } 6 \mathrm{~B}, \mathrm{I} 9 \mathrm{~F}, 23 \mathrm{~F}\end{array}$ \\
\hline \multirow[t]{2}{*}{ PCV10Non7 } & No change & $\begin{array}{l}\text { - Vestiens }{ }^{25} \text { : no significant change up to } 5 \text { years after PCVIo replaced PCV7 (RR I. } 08 \text { (95\% CI } \\
0.3-3.86 \text { ) }\end{array}$ \\
\hline & & - Van Werkhoven ${ }^{38}$ : no significant change pre and up to 2 years post PCVIo \\
\hline \multirow[t]{3}{*}{ Non-vaccine serotypes } & Overall increase & - Horacio ${ }^{28}$ : increase from $27 \cdot 0$ to $4 \mathrm{I} \cdot 9$ between 2010 and $2015(p<0 \cdot 00 \mathrm{I})$ \\
\hline & & $\begin{array}{l}\text { - Van Werkhoven }{ }^{38} \text { : increase in non- } \mathrm{PCV}_{13} \text { STs from } 30 \% \text { pre to } 37 \% \text { in post PCV period (p- } \\
\text { value for trend } 0.048 \text { ) }\end{array}$ \\
\hline & No change & - Quirk ${ }^{48}$ : no significant change pre PCVIo introduction up to 6 years post \\
\hline
\end{tabular}

Table 2: Trends in vaccine serotype and non-vaccine serotype pneumococcal pneumonia after the introduction of infant PCV immunisation.

America, or it may be due to the use of the 24 -valent ss$\mathrm{UAD}$ in the UK and thus a reflection of the types of tests employed. Other factors which may partially explain the finding include differences in the prevalence of tobacco smoking, in pneumococcal vaccine coverage, disparities between healthcare systems and access to antibiotics. ${ }^{65,66,67}$

It was notable in our review that none of the data on VT non-invasive pneumococcal pneumonia were from LMICs. Currently only invasive pneumococci are 
serotyped in most sub-Saharan African countries. One recent study from Malawi using the non-serotype specific BinaxNOW assay suggested that, following introduction of universal infant PCV in 20II, pneumococcal CAP still accounted for $2 \mathrm{I} \cdot 4 \%$ of pneumonias in hospitalised adults. No data on serotype distribution has been described. ${ }^{68}$ A South African study confirmed that ssUAD has high diagnostic accuracy to detect pneumococcal pneumonia and simultaneous detection of PCVI3 serotypes in HIV-infected adults in South Africa, offering a potentially useful tool to determine pneumococcal pneumonia in this population. ${ }^{69}$

Of note is the persistence of $\mathrm{ST}_{3}$ as one of the most prevalent vaccine serotypes both before and after the PCVI3 infant programme. A recent global genomic analysis of $\mathrm{ST}_{3}$ has identified a new antibiotic-resistant clade which is replacing the less resistant clade. ${ }^{70}$ Multiple reports suggest that the indirect protective effects of infant PCV immunisation against IPD in adults is less for $\mathrm{ST}_{3}$ than for other PCV serotypes. ${ }^{\mathrm{I} 2,7 \mathrm{I}-75}$ It has been reported that PCVI3 is less effective at decreasing $\mathrm{ST}_{3}$ colonisation in children, and therefore may be insufficient to indirectly protect older adults. ${ }^{76}$

Our systematic review and meta-analysis has some limitations in addition to those already discussed. Our search strategy sought to identify studies with quantitative data on pneumococcal serotypes, so studies not reporting on serotypes would not have been included in our analysis of the overall proportion of CAP caused by S. pneumoniae. Sampling methods within populations were not standardised across studies and varied from convenience sampling to recruitment of all eligible patients in a cohort and this will affect the overall estimates of proportions. Although we focused on community-acquired infections, we cannot exclude the possibility that some included patients may have had non-community acquired infections. The true incidence of vaccine-type pneumococcal pneumonia is likely to be underestimated from studies which only included patients hospitalised with CAP; there is evidence from several studies that many cases of CAP are not hospitalised and the percentage treated as outpatients or in primary care will vary depend upon the different set up of healthcare systems in different countries., 6,77 Some countries have also introduced adult pneumococcal vaccination policies which may affect variations in the incidence of pneumococcal disease; recommended risk groups may differ between those countries and coverage is likely to vary substantially. As most data were only collected for the period up to five years following the introduction of childhood PCVIo/I3 immunisation, this may not have been sufficient to allow for the development of herd protection.

Based on the findings of the systematic review and meta-analysis we make the following recommendations. First, data on the contribution of pneumococcal serotypes to non-invasive CAP in LMICs are sorely needed to better guide pneumococcal vaccine policy in these regions and tailored vaccine development. The incidence of pneumococcal infection in LMICs is high and pneumococcal vaccines, particularly PCVs, are expensive compared to other vaccines, yet it is not certain that the serotypes included in the current pneumococcal vaccines match the prevailing serotypes causing pneumococcal pneumonia in LMICs. Second, more studies are required to strengthen the evidence on the sero-epidemiology of CAP in older people, as the majority of pneumococcal infections in adults aged $\geq 50$ years are noninvasive yet most of the data come from IPD which is much less common and may be caused by serotypes which do not reflect the pattern of serotypes causing non-invasive pneumonia. Integral to this is the need to develop better serotype-specific diagnostic methods capable of detecting a wider range of serotypes and not restricted to VTs in the existing vaccines so that trends in non-vaccine serotypes can also be detected. This will also be important as new pneumococcal vaccines emerge which cover more serotypes, such as PCVs which are $2 \mathrm{I}$-valent. New diagnostics should not rely on respiratory samples, such as sputum PCR, as 30 to $40 \%$ of adults with pneumonia do not produce sputum and such specimens are prone to contamination or may only reflect carriage..$^{52,78-80}$ Third, we highlight caution when interpreting studies heavily reliant on ss-UADs that target only VT serotypes as they may bias towards over-estimates of the proportions of potentially vaccinepreventable disease.

In conclusion, this review of pneumococcal CAP in adults aged 50 years and over highlights variations in the types of studies and methodologies used to determine the burden of pneumococcal vaccine serotypes. Nonetheless, it demonstrates that there remains a considerable burden of pneumococcal CAP, including potentially vaccine preventable disease, in older people.

\section{Declaration of interests}

WSL reports unrestricted investigator-initiated research funding from Pfizer from 2016 to present for an unrelated multi-centre study in pneumonia in which he is the CI, and research funding for unrelated clinical trials in the fields of COVID-I9, tuberculosis and communityacquired pneumonia. WSL also declares unpaid roles as the Joint Committee on Vaccination and Immunisation (JCVI) UK Chair of COVID-I9 Immunisation, and National Lead of the British Thoracic Society community acquired pneumonia audit programme. LL's salary is funded by the National Institute for Health Research (NIHR) Nottingham Biomedical Research Centre, UK. HL declares voluntary, unpaid membership of the National Confidential Enquiry into Patient Outcome and Death specialist advisory group for Community Acquired Pneumonia. TM and BL declare no competing interests. 


\section{Acknowledgements}

We thank Dr Christos Chalitsios at the University of Nottingham for his technical support.

\section{Contributors}

LL and WSL conceived and designed the study. LL, BL, HL, TM and WSL contributed to the acquisition and extraction of data, quality assessment, and data analysis. LL, WSL and TM interpreted the data. LL wrote the first draft of the manuscript. All authors contributed to critical revision of the manuscript, had full access to all the data in the study, and accept responsibility for the decision to submit for publication.

\section{Data sharing statement}

The study dataset can be requested from Louise.Lansbury@nottingham.ac.uk. The analysis codes are available at https://github.com/LouiseLansbury/Pneumo_serotypes.git.

\section{Funding}

The National Institute for Health Research (NIHR) Nottingham Biomedical Research Centre, UK, provided salary support for this study.

\section{Supplementary materials}

Supplementary material associated with this article can be found, in the online version, at doi:IO.IOI $6 / j$. eclinm.2022.IOI27I.

\section{References}

I Quan TP, Fawcett NJ, Wrightson JM, et al. Increasing burden of community-acquired pneumonia leading to hospitalisation, I9982014. Thorax. 20I6;7I(6):535-542.

2 Welte T, Torres A, Nathwani D. Clinical and economic burden of community-acquired pneumonia among adults in Europe. Thorax. 2012;67(I):7I-79.

3 Cillóniz C, Ewig S, Polverino E, et al. Microbial aetiology of community-acquired pneumonia and its relation to severity. Thorax $2011 ; 66(4): 340-346$.

4 Jain S, Self WH, Wunderink RG, et al. Community-acquired pneumonia requiring hospitalization among U.S. adults. $N$ Engl J Med. 2015;373(5):415-427.

5 Almirall J, Boixeda R, Bolíbar I, et al. Differences in the etiology of community-acquired pneumonia according to site of care: a population-based study. Respir Med. 2007;IOI(I0):2168-2I75.

6 Cillóniz C, Ewig S, Polverino E, et al. Community-acquired pneumonia in outpatients: aetiology and outcomes. Eur Respir J. 20I2;40(4):93I-938.

7 Rice LB. Antimicrobial resistance in gram-positive bacteria. Am J Infect Control. 2006;34(5 Suppl I). SiI-9); discussion S64-73.

8 Bogaert D, De Groot R, Hermans PW. Streptococcus pneumoniae colonisation: the key to pneumococcal disease. Lancet Infect Dis. 2004;4(3):I44-I54.

9 GBD 2016 lower respiratory infections collaborators. Estimates of the global, regional, and national morbidity, mortality, and aetiologies of lower respiratory infections in I95 countries, I990-2016: a systematic analysis for the Global Burden of Disease Study 2016. Lancet Infect Dis. 20I8;I8(II):IIOI-I2IO.

Io Schuchat A, Hilger T, Zell E, et al. Active bacterial core surveillance of the emerging infections program network. Emerg Infect Dis. 200I; $7(\mathrm{I}): 92-99$
II Hanquet G, Krizova P, Valentiner-Branth P, et al. Effect of childhood pneumococcal conjugate vaccination on invasive disease in older adults of Io European countries: implications for adult vaccination. Thorax. 2019;74(5):473-482.

I2 Harboe ZB, Dalby T, Weinberger DM, et al. Impact of I3-valent pneumococcal conjugate vaccination in invasive pneumococcal disease incidence and mortality. Clin Infect Dis. 2014;59(8):I066I073.

I3 Ladhani SN, Collins S, Diennad A, et al. Rapid increase in non-vaccine serotypes causing invasive pneumococcal disease in England and Wales, 2000-I7: a prospective national observational cohort study. Lancet Infect Dis. 20I8;I8(4):44I-45I.

I4 Waight PA, Andrews NJ, Ladhani SN, Sheppard CL, Slack MP Miller E. Effect of the I3-valent pneumococcal conjugate vaccine on invasive pneumococcal disease in England and Wales 4 years after its introduction: an observational cohort study. Lancet Infect Dis. 2015;I5(5):535-543.

I5 Rodrigo C, Bewick T, Sheppard C, et al. Impact of infant I3-valent pneumococcal conjugate vaccine on serotypes in adult pneumonia. Eur Respirat J. 20I5;45(6):I632-I64I.

I6 Frank O, De Oliveira Bernardo C, González-Chica DA, Macartney K, Menzies R, Stocks N. Pneumococcal vaccination uptake among patients aged 65 years or over in Australian general practice. Hum Vaccin Immunother. 2020;16(4):965-971.

I7 Gatwood J, Shuvo S, Hohmeier KC, et al. Pneumococcal vaccination in older adults: an initial analysis of social determinants of health and vaccine uptake. Vaccine. 2020;38(35):5607-56I7.

I8 Moher D, Liberati A, Tetzlaff J, Altman DG. Preferred reporting items for systematic reviews and meta-analyses: the PRISMA statement. BMJ. 2009;339:b2535.

I9 Lansbury L, Lawrence H, Lim B, McKeever T, Lim W-S. The burden of pneumococcal pneumonia due to vaccine-type Streptococcus pneumoniae in adults aged 50 years and over. PROSPERO. 2020: CRD42020I92002. https://www.crd.york.ac.uk/prospero/display_ record.php?ID=CRD42020I92002. Accessed 7 September 202I.

20 Wells G, Shea B, O'Connell D, et al. The Newcastle-Ottawa Scale (NOS) for assessing the quality of nonrandomised studies in metaanalyses. http://www.ohri.ca/programs/clinical_epidemiology/ oxford.asp. Accessed I2 May 202I.

2I Nyaga VN, Arbyn M, Aerts M. Metaprop: a Stata command to perform meta-analysis of binomial data. Arch Public Health. 2014;72 (I):39.

22 Leblanc J, Elsherif M, Ye L, et al. Age-stratified burden of pneumococcal community acquired pneumonia in hospitalised Canadian adults from 2010 to 20I5. BMJ Open Resp Res. 2020;7:e000550.

23 Morimoto K, Suzuki M, Ishifuji T, et al. The burden and etiology of community-onset pneumonia in the aging Japanese population: a multicenter prospective study. PLoS ONE. 2OI5;IO:(3) eOI22247.

24 Menéndez R, España PP, Pérez-Trallero E, et al. The burden of PCVI3 serotypes in hospitalized pneumococcal pneumonia in Spain using a novel urinary antigen detection test. CAPA study. Vaccine. 20I7;35(39):5264-5270.

25 Vestjens SMT, Wagenvoort GHJ, Grutters JC, et al. Changes in pathogens and pneumococcal serotypes causing community-acquired pneumonia in the Netherlands. Vaccine. 20I7:35(33):4II2-4II8.

26 Kim S, Chung D, Song J, et al. Changes in serotype distribution and antimicrobial resistance of Streptococcus pneumoniae isolates from adult patients in Asia: emergence of drug-resistant non-vaccine serotypes. Vaccine. 2019; So264-4IOX(I9):31293-31299. Online ahead of print. https://doi.org/Io.IoI6/j.vaccine.20I9.09.065.

27 Choi MJ, Song JY, Cheong HJ, et al. Clinical usefulness of pneumococcal urinary antigen test, stratified by disease severity and serotypes. J Infect Chemother. 2015;2I(9):672-679.

28 Horácio AN, Silva-Costa C, Lopes E, Ramirez M, M-C J. Conjugate vaccine serotypes persist as major causes of non-invasive pneumococcal pneumonia in Portugal despite declines in serotypes 3 and I9A (20I2-20I5). PLoS ONE. 20I8;I3:(II) eo2069I2.

29 Noguchi S, Yatera K, Akata K, et al. Distribution and annual changes in the proportion of Streptococcus pneumoniae serotypes in Japanese adults with pneumococcal pneumonia from 20 II to 20I7. J Infect Chemother. 20I9;25(II):925-929.

30 Regev-Yochay GC, Chazan B, Gonzalez E, et al. Distribution of I3Valent pneumococcal conjugate vaccine serotype streptococcus pneumoniae in adults 50 Years and older presenting with communityacquired pneumonia in Israel. Hum Vaccin Immunother. 20I8;I4 (IO):2527-2532.

3I Sherwin RL, Gray S, Alexander R, et al. Distribution of I3-valent pneumococcal conjugate vaccine Streptococcus pneumoniae 
serotypes in US adults aged $\geq 50$ years with community-acquired pneumonia. J Infect Dis. 20I3;208(II):I8I3-I820.

32 Oishi K, Yoshimine H, Watanabe H, et al. Drug-resistant genes and serotypes of pneumococcal strains of community-acquired pneumonia among adults in Japan. Respirology. 2006;II(4):429-436.

33 Prato R, Fortunato F, Cappelli MG, Chironna M, Martinelli D. Effectiveness of the I3-valent pneumococcal conjugate vaccine against adult pneumonia in Italy: a case-control study in a 2-year prospective cohort. BMJ Open. 20I8;8:(3) eoI9034.

34 Pletz MW, Ewig S, Rohde G, et al. Impact of pneumococcal vaccination in children on serotype distribution in adult community acquired pneumonia using the serotype-specific multiplex urinary antigen detection assay. Vaccine. 2016;34(20):2342-2348.

35 Sando E, Suzuki M, Furumoto A, et al. Impact of the pediatric I3valent pneumococcal conjugate vaccine on serotype distribution and clinical characteristics of pneumococcal pneumonia in adults: the Japan Pneumococcal Vaccine Effectiveness Study (J-PAVE) Vaccine. 20I9:(37):2687-2693.

36 Horácio AN, Lopes JP, Ramirez M, Melo-Cristino J. Non-invasive pneumococcal pneumonia in Portugal-serotype distribution and antimicrobial resistance. PLoS ONE. 20I4;9:(7) eI03092.

37 Wunderink RG, Self WH, Anderson EJ, et al. Pneumococcal community-acquired pneumonia detected by serotype-specific urinary antigen detection assays. Clin Infect Dis. 20I8;66(IO):I504-I5IO.

38 van Werkhoven CH, Hollingsworth RC, Huijts SM, et al. Pneumococcal conjugate vaccine herd effects on non-invasive pneumococcal pneumonia in elderly. Vaccine. 2016;34(28):3275-3282.

39 Isturiz RE, Ramirez J, Self WH, et al. Pneumococcal epidemiology among us adults hospitalized for community-acquired pneumonia. Vaccine. 20I9;37(25):3352-336I.

40 Vila-Corcoles A, Ansa X, Ochoa-Gondar O, Satue E, de Diego C, Rodriguez-Blanco T. Pneumococcal pneumonia in adults 60 years or older: incidence, mortality and prevention. Med Clin. 2016;I46 (5):I99-202.

4I Pick H, Daniel P, Rdrigo C, et al. Pneumococcal serotype trends, surveillance and risk factors in UK adult pneumonia, 20I3-I8. Tho rax. 2020;75:38-49.

42 Harat RA, Gray S, Gutterman EM, et al. Prospective, population-based surveillance of the burden of Streptococcus pneumoniae in community-acquired pneumonia in older adults, Chrzanów County, Poland 2010 to 20I2. Pneumonol Alergol Pol. 20I6;84(2):95-IO3.

43 Benfield T, Skovgaard M, Schønheyder HC, et al. Serotype distribution in non-bacteremic pneumococcal pneumonia: association with disease severity and implications for pneumococcal conjugate vac cines. PLoS ONE. 2013;8(8):e72743.

44 Di Pasquale M, Aliberti S, Azzari C, et al. Serotypes and antibiotic susceptibility of Streptococcus pneumoniae isolated from hospital ized patients with community-acquired pneumonia in Italy. SAGE Open Med. 20I7;5:I-4.

45 Domenech A, Ardanuy C, Calatayud L, et al. Serotypes and genotypes of Streptococcus pneumoniae causing pneumonia and acute exacerbations in patients with chronic obstructive pulmonary disease. J Antimicrob Chemother. 2011;66(3):487-493.

46 Suzuki M, Dhoubhadel BG, Ishifuji T, et al. Serotype-specific effectiveness of 23-valent pneumococcal polysaccharide vaccine agains pneumococcal pneumonia in adults aged 65 years or older: a multicentre, prospective, test-negative design study. Lancet Infect Dis 2OI7;I7(3):3I3-32I.

47 LeBlanc J, ElSherif M, Ye L, et al. Streptococcus pneumoniae serotype 3 is masking PCVI3-mediated herd immunity in Canadian adults hospitalized with community acquired pneumonia: a study from the Serious Outcomes Surveillance (SOS) Network of the Canadian immunization research Network (CIRN). Vaccine. 20I9;37:5466-5473

48 Quirk SJ, Haraldsson G, Hjálmarsdóttir MÁ, et al. Vaccination of Icelandic children with the Io-valent pneumococcal vaccine leads to a significant herd effect among adults in Iceland. J Clin Microbiol. 20I9;57(4).

49 Eletu SD, Sheppard CL, Rose S, et al. Re-validation and update of an extended-specificity multiplex assay for detection of Streptococcus pneumoniae capsular serotype/serogroup-specific antigen and cell-wall polysaccharide in urine specimens. Access Microbiol. 2020;2(3): acmioooo94.

50 Eletu SD, Sheppard CL, Thomas E, et al. Development of an extended-specificity multiplex immunoassay for detection of Streptococcus pneumoniae serotype-specific antigen in urine by use of human monoclonal antibodies. Clin Vaccine Immunol. 20I7;24(I2).
5I Sheppard CL, Harrison TG, Smith MD, George RC. Development of a sensitive, multiplexed immunoassay using xMAP beads for detection of serotype-specific streptococcus pneumoniae antigen in urine samples. J Med Microbiol. 20II;6o(Pt I):49-55.

52 Song JY, Eun BW, Nahm MH. Diagnosis of pneumococcal pneumonia: current pitfalls and the way forward. Infect Chemother. 20I3;45(4):35I-366.

53 Boulware DR, Daley CL, Merrifield C, Hopewell PC, Janoff EN. Rapid diagnosis of pneumococcal pneumonia among HIV-infected adults with urine antigen detection. J Infect. 2007;55(4):300-309.

54 Said MA, Johnson HL, Nonyane BA, et al. Estimating the burden of pneumococcal pneumonia among adults: a systematic review and meta-analysis of diagnostic techniques. PLOS ONE. 2013;8(4): e60273.

55 Horita N, Miyazawa N, Kojima R, et al. Sensitivity and specificity of the Streptococcus pneumoniae urinary antigen test for unconcentrated urine from adult patients with pneumonia: a meta-analysis. Respirology. 20I3;I8(8):II77-II83.

56 Sinclair A, Xie X, Teltscher M, Dendukuri N. Systematic review and meta-analysis of a urine-based pneumococcal antigen test for diagnosis of community-acquired pneumonia caused by Streptococcus pneumoniae. J Clin Microbiol. 2013;51(7):2303-2310.

57 Domínguez J, Galí N, Blanco S, et al. Detection of Streptococcus pneumoniae antigen by a rapid immunochromatographic assay in urine samples. Chest. 200I;II9(I):243-249.

58 Gutiérrez F, Masiá M, Rodríguez JC, et al. Evaluation of the immunochromatographic Binax NOW assay for detection of Streptococcus pneumoniae urinary antigen in a prospective study of community-acquired pneumonia in Spain. Clin Infect Dis. 2003:36 (3):286-292.

59 Rosón B, Fernández-Sabé N, Carratalà J, et al. Contribution of a urinary antigen assay (Binax NOW) to the early diagnosis of pneumococcal pneumonia. Clin Infect Dis. 2004;38(2):222-226.

60 Smith MD, Derrington P, Evans R, et al. Rapid diagnosis of bacteremic pneumococcal infections in adults by using the Binax NOW Streptococcus pneumoniae urinary antigen test: a prospective, controlled clinical evaluation. I Clin Microbiol. 2003:4I(7):28IO-28I3.

6I Shoji H, Domenech A, Simonetti AF, et al. The Alere BinaxNOW pneumococcal urinary antigen test: diagnostic sensitivity for adult pneumococcal pneumonia and relationship to specific serotypes. $J$ Clin Microbiol. 2018;56(2)

62 Musher DM, Abers MS, Bartlett JG. Evolving understanding of the causes of pneumonia in adults, with special attention to the role of pneumococcus. Clin Infect Dis. 2017;65(I0):I736-I744.

63 Shoar S, Musher DM. Etiology of community-acquired pneumonia in adults: a systematic review. Pneumonia. 2020;I2:II.

64 Torres A, Blasi F, Dartois N, Akova M. Which individuals are at increased risk of pneumococcal disease and why? Impact of COPD, asthma, smoking, diabetes, and/or chronic heart disease on community-acquired pneumonia and invasive pneumococcal disease. Thorax. 20I5;70(I0):984-989.

65 Jamal A, Phillips E, Gentzke AS, et al. Current Cigarette Smoking Among Adults - United States, 20I6. MMWR Morb Mortal Wkly Rep. 20I8;67(2):53-59.

66 WHO Regional Office for Europe. Health Topics Tobacco https:// www.euro.who.int/en/health-topics/disease-prevention/tobacco. Accessed I2 May 202I.

67 Norris T, Vahratian A, Cohen RA. Vaccination coverage among adults aged 65 and over: united States. NCHS Data Brief. 20I5;20I7 (28I):I-8.

68 Aston SJ, Ho A, Jary H, et al. Etiology and risk factors for mortality in an adult community-acquired pneumonia cohort in Malawi. Am J Respir Crit Care Med. 2019;200(3):359-369.

69 Albrich WC, Pride MW, Madhi SA, et al. Multiplex urinary antigen detection for I3 Streptococcus pneumoniae serotypes improves diagnosis of pneumococcal pneumonia in South African HIV-infected adults. J Clin Microbiol. 20I7;55(I):302-3I2.

70 Azarian T, Mitchell PK, Georgieva M, et al. Global emergence and population dynamics of divergent serotype 3 CCI8o pneumococci. PLoS Pathog. 20I8;I4:(II) eI007438.

7I Horacio A, Silva-Costa C, Lopez JP, Ramirez M, Melo-Cristino J. Serotype 3 remains the leading cause of invasive pneumococcal disease in adults in Portugal (2OI2-20I4) despite continued reductions in other I3-valent conjugate vaccine serotypes. Front Microbiol. 20I6;7(I6I6).

72 van der Linden M, Falkenhorst G, Perniciaro S, Imöhl M. Effects of infant pneumococcal conjugate vaccination on serotype distribution in invasive pneumococcal disease among children and adults in Germany. PLOS ONE. 20I5;IO:(7) eoI3I494. 
73 Steens A, Bergsaker MA, Aaberge IS, Rønning K, Vestrheim DF. Prompt effect of replacing the 7 -valent pneumococcal conjugate vaccine with the I3-valent vaccine on the epidemiology of invasive pneumococcal disease in Norway. Vaccine. 20I3;3I(52):6232-6238.

74 Galanis I, Lindstrand A, Darenberg J, et al. Effects of PCV7 and PCVI3 on invasive pneumococcal disease and carriage in Stockholm, Sweden. Eur Respir J. 20I6;47(4):I208-I2I8.

75 Moore MR, Link-Gelles R, Schaffner W, et al. Effect of use of I3-valent pneumococcal conjugate vaccine in children on invasive pneumococcal disease in children and adults in the USA: analysis of multisite, population-based surveillance. Lancet Infect Dis. 20I5; I5 (3):30I-309.

76 Dagan R, Patterson S, Juergens C, et al. Comparative immunogenicity and efficacy of I3-valent and 7-valent pneumococcal conjugate vaccines in reducing nasopharyngeal colonization: a randomized double-blind trial. Clin Infect Dis. 2013;57(7):952-962.
77 Woodhead MA, Macfarlane JT, McCracken JS, Rose DH, Finch RG. Prospective study of the aetiology and outcome of pneumonia in the community. Lancet. I987;I(8534):67I-674.

78 García-Vázquez E, Marcos MA, Mensa J, et al. Assessment of the usefulness of sputum culture for diagnosis of community-acquired pneumonia using the PORT predictive scoring system. Arch Intern Med. 2004;I64(I6):I807-I8II.

79 Musher DM, Montoya R, Wanahita A. Diagnostic value of microscopic examination of Gram-stained sputum and sputum cultures in patients with bacteremic pneumococcal pneumonia. Clin Infect Dis. 2004;39(2):165-169.

80 van der Eerden MM, Vlaspolder F, de Graaff CS, et al. Comparison between pathogen directed antibiotic treatment and empirical broad spectrum antibiotic treatment in patients with community acquired pneumonia: a prospective randomised study. Thorax. $2005 ; 60(8): 672-678$. 